\title{
Broadening, no broadening and narrowing of glass transition of supported polystyrene ultrathin films emerging under ultraslow temperature variations
}

\author{
Chunming Yang and Isao Takahashi \\ We report X-ray reflectivity measurements of polystyrene thin films supported on Si substrates at various heating and cooling \\ rates. At a heating rate of $0.05{ }^{\circ} \mathrm{C} \mathrm{min}^{-1}$, the width of the glass transition $w$ does not show any noticeable thickness \\ dependence. However, at faster $\left(0.5^{\circ} \mathrm{C} \mathrm{min}-1\right)$ and slower $\left(0.01{ }^{\circ} \mathrm{C} \mathrm{min}{ }^{-1}\right)$ heating rates, $w$ shows remarkable thickness \\ dependence: it broadens at a faster rate and narrows at a slower rate with decreasing film thickness. Our results suggest that \\ the heterogeneous character of the dynamics can be transformed into a homogeneous one in a glassy film with thickness \\ comparable to a critical thickness that depends on the rate of temperature variation.
}

Polymer Journal (2011) 43, 390-397; doi:10.1038/pj.2010.145; published online 19 January 2011

Keywords: confinement effects; glass transition; polymer thin films; transition breadth; transition broadening; X-ray reflection

\section{INTRODUCTION}

The molecular dynamics in liquid, especially close to and below the glass transition temperature $T_{\mathrm{g}}$, are very heterogeneous. ${ }^{1}$ From a theoretical viewpoint in which the mean structural relaxation in glassy systems occurs through rearrangements of correlated particles, the spatial particle region surrounded by other subsystems composed of particles with differing mobilities is called a cooperatively rearranging region. ${ }^{2,3}$ Because of the dynamic heterogeneity, temporal relaxations depend on the subsystems, and the glass transition generally occurs within a certain temperature range called the width of glass transition $w$. Polymers confined in a particular size of cooperatively rearranging region can be good candidates for investigating the spatial size of dynamic heterogeneities. A striking result in confined systems is that $T_{\mathrm{g}}$ of thin films often exhibits a remarkable thickness dependence., ${ }^{4,5}$ This result strongly suggests that interfaces in a confined system have an important role. Many studies have revealed the properties of interfacial regions and have provided extensive evidence that the molecular mobility is much higher in the free surface region than in the bulk region at the same temperature $;^{6-9}$ dynamics near the free surface are very fast. On the other hand, the interaction between a polymer and a solid substrate can suppress molecular relaxation in an interfacial region, leading to peculiar slower dynamics in this region. ${ }^{9-13}$ Measurements of the relaxation rate using a 20 -nm-thick fluorescently labeled layer that has been incorporated into polymer films have revealed that the rate of dynamics depends on the distance from both the free surface and the interface. These dynamics vary continuously, exhibiting bulk-like characteristics toward the interior layer sandwiched between the surface and the interfacial layers. ${ }^{9}$
In the first report on the strong dynamic heterogeneity in polymers under confined geometry, second harmonic generation measurements on probe-doped thin polymer films revealed that the distribution of relaxation time broadens with decreasing thickness. ${ }^{14}$ Dielectric investigations of thin films supported on aluminum substrates have shown that the full width at half maximum of dielectric loss increases with decreasing thickness, suggesting that a decrease in $T_{\mathrm{g}}$ is directly related to the broadening of the $\alpha$-relaxation peak. ${ }^{15,16}$ Ellipsometric measurement of thermal expansivity in supported polystyrene (PS) thin films has shown that the upper extreme of glass transition, $T_{+}$, remains at a point close to the bulk $T_{\mathrm{g}}$, whereas the lower extreme, $T_{-}$, continuously decreases with decreasing film thickness, suggesting a broadening of glass transition in films thinner than $30 \mathrm{~nm} .{ }^{17}$ However, such a broadening has not been observed in free-standing films. ${ }^{18,19}$ Measurement of dielectric loss at around $1 \mathrm{kHz}$ on thin poly(methylmethacrylate) films having a free upper interface has revealed that the full width at half maximum of the $\alpha$-relaxation peak broadens with decreasing thickness. ${ }^{20}$ However, such variation of the width of the glass transition was not observed in another dielectric loss study conducted at lower frequencies $(0.12$ and $0.01 \mathrm{~Hz}){ }^{21}$ Ellipsometric measurements taken at various cooling rates for supported PS thin films have revealed that the width of the glass transition is almost independent of film thickness at a fast cooling rate $\left(130^{\circ} \mathrm{C} \mathrm{min}^{-1}\right)$, whereas measurements taken at slower cooling rates $\left(1\right.$ and $\left.3^{\circ} \mathrm{Cmin}^{-1}\right)$ show the width of the glass transition broadening with decreasing thickness. ${ }^{22}$ Study of faster dynamics using a calorimeter, with ultrafast heating rates ranging from $1.8 \times 10^{6}$ to $2.4 \times 10^{6}{ }^{\circ} \mathrm{C} \mathrm{min}^{-1}$, has revealed that the width of the 
transition at this rate becomes broader as the thickness decreases. ${ }^{23}$ Although the dynamics of ultrathin glassy polymers have been investigated extensively, information on ultraslow dynamics is still lacking. In this study, we investigate the relationship between glass transition temperature and the width of the glass transition in supported PS thin films, using X-ray reflectivity (XR) at slow heating and cooling rates ranging from 0.5 to $0.01{ }^{\circ} \mathrm{C} \mathrm{min}^{-1}$.

\section{EXPERIMENTAL PROCEDURE}

The materials used in this study were atactic PS (Polymer Source, Montreal, Canada) samples with various molecular weights $\left(M_{\mathrm{w}}=5.2 \times 10^{4} \mathrm{~g} \mathrm{~mol}^{-1}\right.$, $M_{\mathrm{w}} / M_{\mathrm{n}}=1.04, R_{\mathrm{g}} \sim 6 \mathrm{~nm} ; M_{\mathrm{w}}=2.34 \times 10^{5} \mathrm{~g} \mathrm{~mol}^{-1}, M_{\mathrm{w}} / M_{\mathrm{n}}=1.04, R_{\mathrm{g}} \sim 12 \mathrm{~nm} ;$ and $\left.M_{\mathrm{w}}=8.35 \times 10^{5} \mathrm{~g} \mathrm{~mol}^{-1}, M_{\mathrm{w}} / M_{\mathrm{n}}=1.08, R_{\mathrm{g}} \sim 24 \mathrm{~nm}\right)$. The thin films were made by spin-coating (at 4000 r.p.m.) PS dissolved in toluene on $\mathrm{Si}$ (100) wafer capped with natural silicon oxide. After spin-coating, all the samples were annealed in vacuum at $127^{\circ} \mathrm{C}$ for $12 \mathrm{~h}$ before cooling to room temperature over a period of $4 \mathrm{~h}$. Because samples with a higher PS molecular weight $\left(M_{\mathrm{w}}=2.34 \times 10^{5}\right.$ and $\left.8.35 \times 10^{5} \mathrm{~g} \mathrm{~mol}^{-1}\right)$ showed a persistent thermal history after annealing, including the negative expansivity in the glassy state particularly seen in thinner films, the samples were subjected to additional heating and cooling cycles in a vacuum chamber over a period of a few hours till they showed normal expansivity. Before the XR data acquisition, uniformity of the polymer surface was confirmed using atomic force microscopy. Specular XR spectra at various temperatures were observed using a high-resolution four-circle $\mathrm{X}$-ray diffractometer with a rotating-anode X-ray generator (SLX2000+Ultra-X, Rigaku Co., Akishima, Japan). CuK $\alpha_{1}$ radiation (wavelength $\lambda=0.15406 \mathrm{~nm}$ ) was monochromated using a two-bounce Ge (220) crystal monochromator. During the data collection at isothermal steps, samples were kept in a dry nitrogen atmosphere. The sample temperature was controlled using a homemade heater and a thyristor regulator temperature controller (SU12AM241MSNNNN, CHINO, Tokyo, Japan) that had an accuracy of $\pm 0.2^{\circ} \mathrm{C}$. At each temperature, it took $\sim 25 \mathrm{~min}$ for collecting each XR. After measuring XR at a particular temperature, the samples were heated by $5{ }^{\circ} \mathrm{C}$ at a constant heating rate $\left(0.5,0.05\right.$ and $\left.0.01{ }^{\circ} \mathrm{C} \mathrm{min}^{-1}\right)$, from room temperature to $130^{\circ} \mathrm{C}$. After heating, some of the samples were cooled at the same rate for data collection under cooling. The observed XR $I_{\operatorname{Exp}}(i)$ accumulated at a momentum transfer $Q_{i}=4 \pi \sin \theta_{i} / \lambda(i=1, M)$ was fitted by a three-layer model, where the calculated XR $I_{\text {cal }}(i)$ was obtained by assuming three layers: air, PS thin film and $\mathrm{Si}$ substrate. Here, $\theta_{i}$ is the $i$-th incident angle in each data set, and the typical value of $M$ lies between 300 and 500. Although we assumed a relatively simplelayered structure, least-square fittings yielded a sufficiently small reliability factor $R\left(=\Sigma_{1}^{M}\left|I_{\exp }(i)-I_{\text {cal }}(i)\right| / \Sigma_{1}^{M} I_{\exp }(i)\right)$ between 0.010 and 0.015 , indicating a markedly smooth and uniform PS layer on very flat $\mathrm{Si}(100)$; the precision of thickness of the PS layer was estimated to be $0.01 \mathrm{~nm}$ for all the XR analyses. Typical XR profiles of a thicker film $(61.21 \mathrm{~nm})$ and a thinner film $(6.33 \mathrm{~nm})$ observed at $27^{\circ} \mathrm{C}$ are shown in Figure 1 . The agreement between the fitted curves (solid lines) and observation is excellent.

\section{RESULTS}

Figure 2 shows the temperature dependence of thickness $h(T)$ of the thicker PS films having a molecular weight of $2.34 \times 10^{5} \mathrm{~g} \mathrm{~mol}^{-1}$. The solid curves in the figure were fitted to the data by the following 'tanh' profile approximation: ${ }^{19}$

$$
h(T)=w\left(\frac{M-G}{2}\right) \ln \left[\cosh \left(\frac{T-T_{\mathrm{g}}}{w}\right)\right]+\left(T-T_{\mathrm{g}}\right)\left(\frac{M+G}{2}\right)+c,
$$

where $w$ and $c$ represent the width of the glass transition and the film thickness at $T=T_{\mathrm{g}}$, respectively. As $M$ and $G$ correspond to the slope of the curve extrapolated to the lowest and highest temperatures, respectively, they were separately obtained by a linear fit to the data in both the rubbery and the glassy regime and were considered as constants in the fitting of Equation (1). The dashed lines in the figures represent the fitted lines, the intersection of which represents $T_{\mathrm{g}}$.
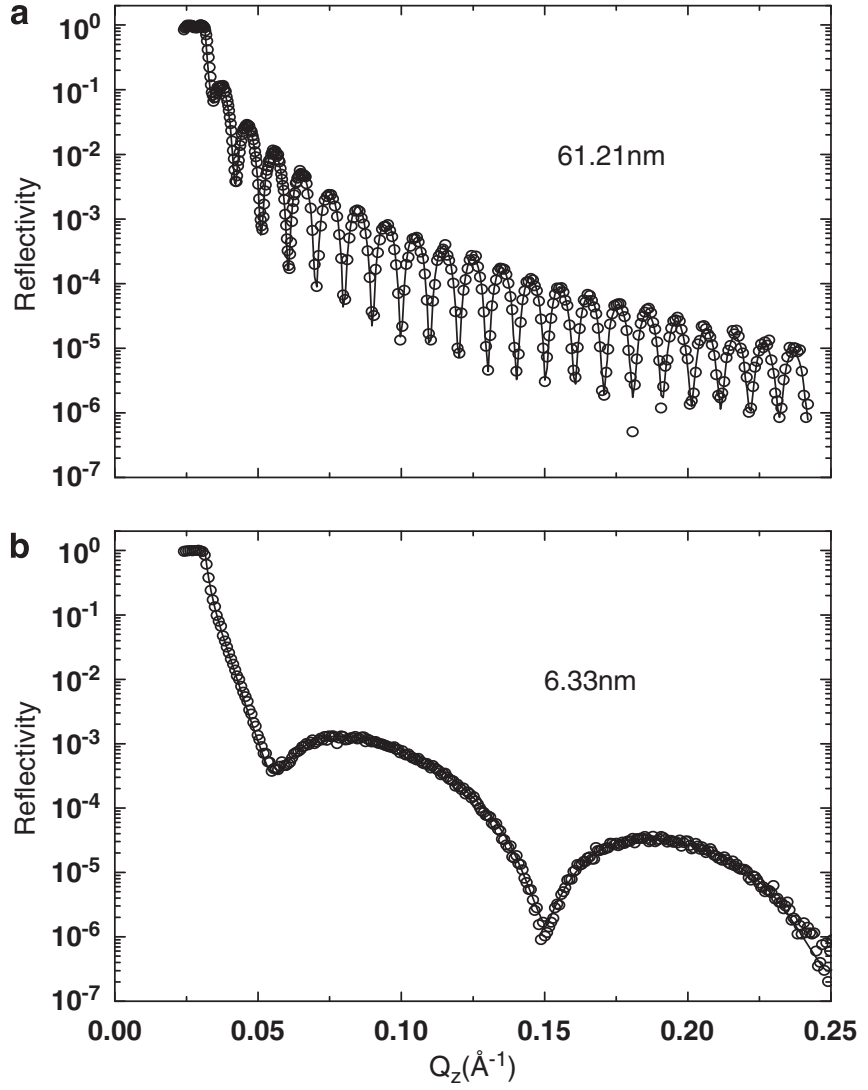

Figure 1 Typical X-ray reflectivity profiles of polystyrene films (thicknesses: $61.21 \mathrm{~nm}(\mathbf{a})$ and $6.33 \mathrm{~nm}(\mathbf{b}))$ measured at room temperature. Solid curves are the results of fits.

Judging from the agreement between the observed PS film thickness $h(T)$ and the solid curve, the tanh-profile model seems to be useful for describing the temperature dependence of $h(T)$. Figure 2a shows results for heating/cooling at a rate of $0.5^{\circ} \mathrm{C} \mathrm{min}^{-1}$, where $T_{\mathrm{g}}$ in the heating process was determined to be $95.3 \pm 0.5^{\circ} \mathrm{C}$, which is slightly higher than $T_{\mathrm{g}}\left(92.5 \pm 0.5^{\circ} \mathrm{C}\right)$ determined in the subsequent cooling process. The value of $w$ was determined to be $10.0 \pm 0.8^{\circ} \mathrm{C}$ in the heating process and $9.0 \pm 0.5^{\circ} \mathrm{C}$ in the cooling process. For the ultraslow heating rate of $0.01^{\circ} \mathrm{Cmin}^{-1}$ (Figure 2b), $T_{\mathrm{g}}$ was determined to be $89.0 \pm 0.5^{\circ} \mathrm{C}$, which is slightly lower than $T_{\mathrm{g}}\left(90.6^{\circ} \mathrm{C}\right)$ of a bulk PS sample heated at the same rate. ${ }^{24}$ The obtained value of $w$ $\left(9.0 \pm 0.5^{\circ} \mathrm{C}\right)$ is almost comparable to the $w$ determined at the rate of $0.5^{\circ} \mathrm{C} \mathrm{min}{ }^{-1}$.

Figure 3 shows the temperature dependence of the thickness of thinner films prepared with PS of a molecular weight of $8.35 \times 10^{5} \mathrm{~g} \mathrm{~mol}^{-1}$. The thicknesses at room temperature were $h_{0}=11.40 \mathrm{~nm}$ (a) and $h_{0}=6.31 \mathrm{~nm}$ (b). The sample was subjected to a first cooling, subsequent heating and then a second cooling at a rate of $0.5^{\circ} \mathrm{C} \mathrm{min}{ }^{-1}$. In the repeated heating/cooling processes, $T_{\mathrm{g}}$ was determined to be $82.5 \pm 0.6^{\circ} \mathrm{C}$ (first cooling), $77.0 \pm 0.5^{\circ} \mathrm{C}$ (subsequent heating) and $85.0 \pm 1.0^{\circ} \mathrm{C}$ (second cooling). $T_{\mathrm{g}}$ in the first cooling was close to that in the second cooling, which is consistent with a previous report in which $T_{\mathrm{g}}$ was measured at a rate of $1{ }^{\circ} \mathrm{C} \mathrm{min}^{-1}\left(T_{\mathrm{g}}=82^{\circ} \mathrm{C}\right) .{ }^{25}$ The values of $w$ obtained in the first cooling $\left(14.0 \pm 0.5^{\circ} \mathrm{C}\right)$, the subsequent heating $\left(14.0 \pm 0.6^{\circ} \mathrm{C}\right)$ and the second cooling $\left(16.0 \pm 1.0^{\circ} \mathrm{C}\right)$ do not show significant variation. During the ultraslow cooling process $\left(0.01^{\circ} \mathrm{C} \mathrm{min}{ }^{-1}\right), T_{\mathrm{g}}$ and $w$ were determined 

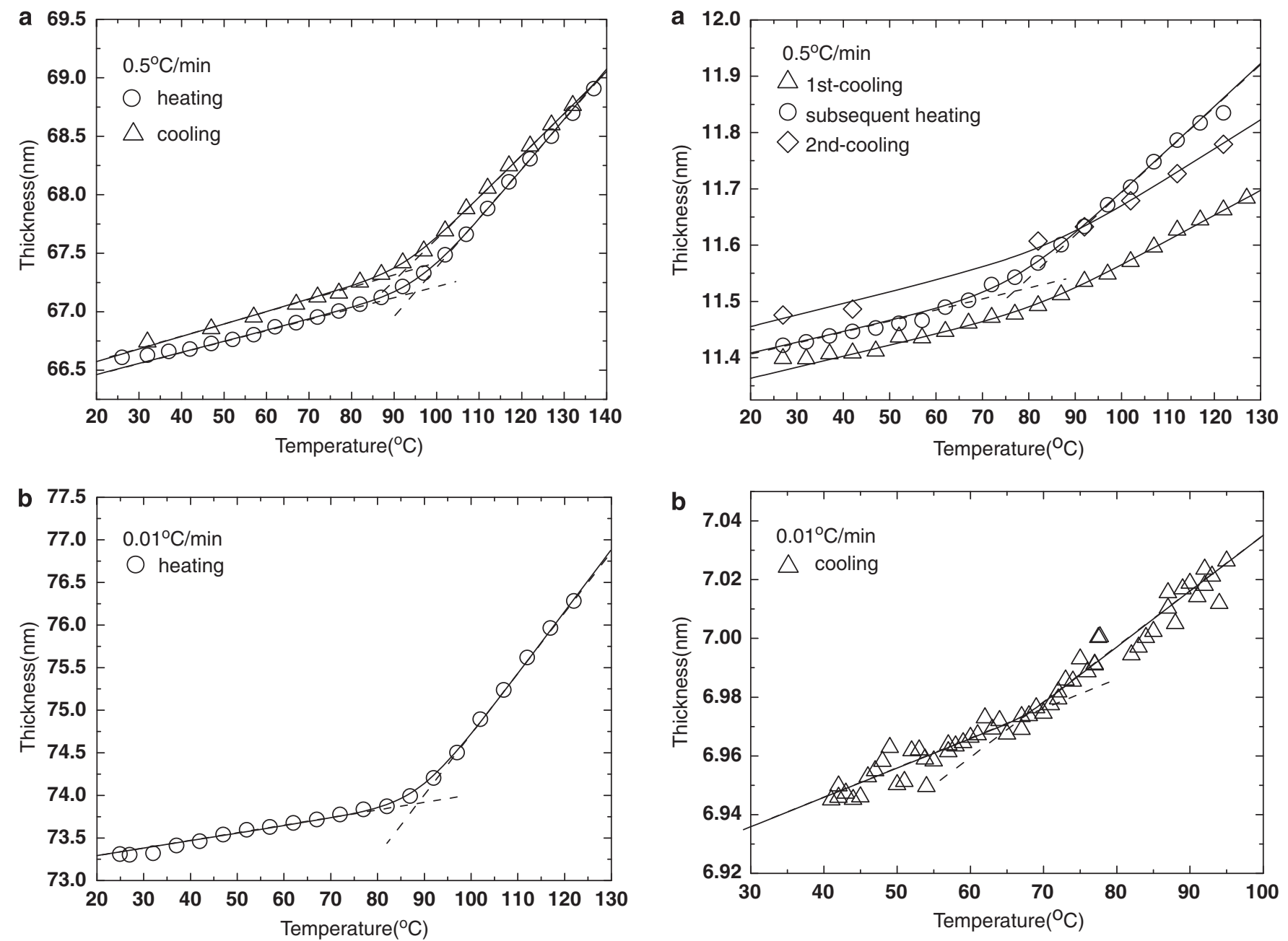

Figure 2 Temperature dependence of film thickness $\left(M_{\mathrm{w}}=2.34 \times 10^{5} \mathrm{~g} \mathrm{~mol}^{-1}\right)$ for (a) a 66.60-nm-thick film measured at a faster heating and cooling rate of $0.5^{\circ} \mathrm{C} \mathrm{min}^{-1}$, and (b) a 73.31-nm-thick film measured at an ultraslow heating rate of $0.01{ }^{\circ} \mathrm{C} \mathrm{min}^{-1}$. The symbol $\Delta$ in panel a represents a subsequent cooling process after the initial heating. Solid lines in the figures are the results of fits.

to be $67.5 \pm 0.6{ }^{\circ} \mathrm{C}$ and $2 \pm 1{ }^{\circ} \mathrm{C}$, respectively. These values are significantly lower than the values observed in the faster cooling processes (Figure 3a).

These results show that, in thicker films, $w$ does not exhibit a heating/cooling rate dependence, whereas in the thinner films, $w$ shows a strong rate dependence. These features are consistent with the results of dielectric spectroscopy, in which a clear frequency dependence of the glass transition is presented. ${ }^{21,26}$

Figure 4 shows the temperature dependence of thickness when the samples were heated at a rate of $0.5^{\circ} \mathrm{C} \mathrm{min}^{-1}\left(M_{\mathrm{w}}=5.2 \times 10^{4} \mathrm{~g} \mathrm{~mol}^{-1}\right)$. The initial values of thickness at room temperature $h_{0}$ and $w$ were (a) $59.50 \mathrm{~nm}$ and $10 \pm 2{ }^{\circ} \mathrm{C}$, (b) $23.83 \mathrm{~nm}$ and $14 \pm 2{ }^{\circ} \mathrm{C}$, (c) $12.40 \mathrm{~nm}$ and $15 \pm 1{ }^{\circ} \mathrm{C}$ and (d) $6.40 \mathrm{~nm}$ and $21 \pm 2{ }^{\circ} \mathrm{C}$, respectively. The trend in $w$ clearly shows the broadening of the glass transition, especially for thinner films. Figure 5 shows the temperature dependence of thickness when the samples were heated at a rate of $0.05^{\circ} \mathrm{C} \mathrm{min}-1$ $\left(M_{\mathrm{w}}=5.2 \times 10^{4} \mathrm{~g} \mathrm{~mol}^{-1}\right)$. The initial values of thickness at room temperature $h_{0}$ and $w$ were (a) $59.50 \mathrm{~nm}$ and $12 \pm 2{ }^{\circ} \mathrm{C}$, (b) $23.90 \mathrm{~nm}$ and $12 \pm 1{ }^{\circ} \mathrm{C}$, (c) $12.20 \mathrm{~nm}$ and $12 \pm 1^{\circ} \mathrm{C}$ and (d) $5.80 \mathrm{~nm}$

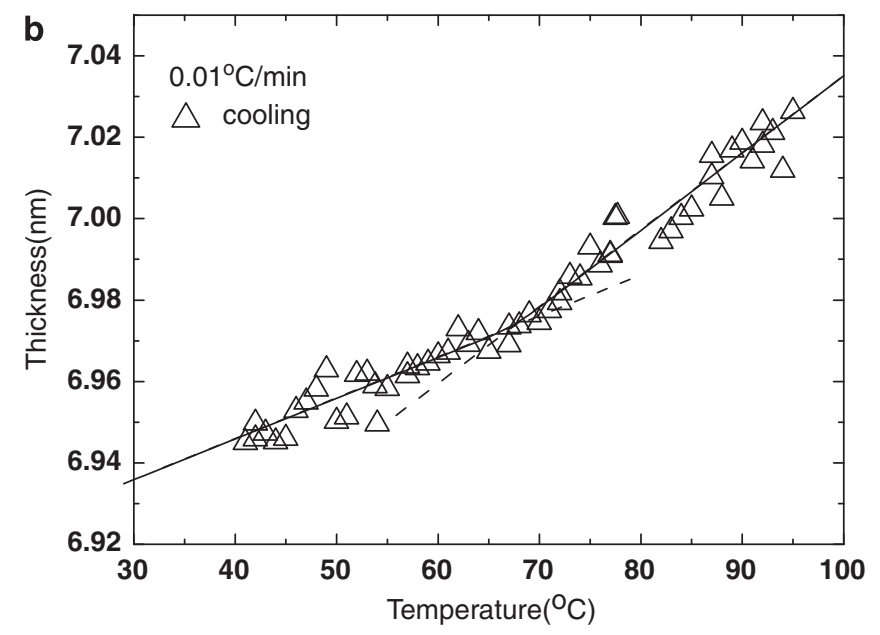

Figure 3 Temperature dependence of film thickness $\left(M_{\mathrm{w}}=8.35 \times 10^{5} \mathrm{~g} \mathrm{~mol}^{-1}\right)$ for (a) a polystyrene (PS) film with $h_{0}=11.40 \mathrm{~nm}$ measured at a faster heating/ cooling rate of $0.5^{\circ} \mathrm{C} \mathrm{min}^{-1}$ and (b) a PS film with $h_{0}=6.31 \mathrm{~nm}$ measured at an ultraslow heating rate of $0.01{ }^{\circ} \mathrm{C} \mathrm{min}^{-1}$, where $h_{0}$ is initial thicknesses at room temperature. The symbol $\bigcirc$ in panel a represents a subsequent heating after the initial cooling, which is represented by the symbol $\Delta$. The symbol $\diamond$ represents the second cooling process. Solid lines in the figures are the results of fits.

and $12 \pm 1{ }^{\circ} \mathrm{C}$, showing no apparent dependence of $w$ on $h_{0}$. In the case of an ultraslow rate of $0.01^{\circ} \mathrm{C} \mathrm{min}^{-1}$ (Figure 6, $M_{\mathrm{w}}=5.2 \times 10^{4} \mathrm{~g} \mathrm{~mol}^{-1}$ ), the initial values of thickness at room temperature $h_{0}$ and $w$ were (a) $61.10 \mathrm{~nm}$ and $14 \pm 2{ }^{\circ} \mathrm{C}$, (b) $26.20 \mathrm{~nm}$ and $12 \pm 2{ }^{\circ} \mathrm{C}$, (c) $12.10 \mathrm{~nm}$ and $11 \pm 2{ }^{\circ} \mathrm{C}$ (cooling), (d) $6.30 \mathrm{~nm}$ and $6 \pm 1{ }^{\circ} \mathrm{C}$, (e) $5.95 \mathrm{~nm}$ and $4.5 \pm 1.0^{\circ} \mathrm{C}$ (cooling) and (f) $3.80 \mathrm{~nm}$ and $2 \pm 1{ }^{\circ} \mathrm{C}$, showing a striking decrease in $w$ with decreasing $h_{0}$ (a narrowing of the glass transition). These results are in sharp contrast to the broadening of the glass transition observed at a rate of $0.5^{\circ} \mathrm{C} \mathrm{min}^{-1}$ (Figure 4).

\section{DISCUSSION}

Figure 7 shows the logarithm of $w$ plotted as a function of reciprocal thickness $1 / h$. An approximate linear relationship between $\log (w)$ and $1 / h$ seems to hold. The solid lines in Figure 7 represent the result of fit to the following equation:

$$
\log (w)=\log \left(w_{\infty}\right)+k(q)\left(\frac{1}{h}-\frac{1}{h_{c}(q)}\right),
$$



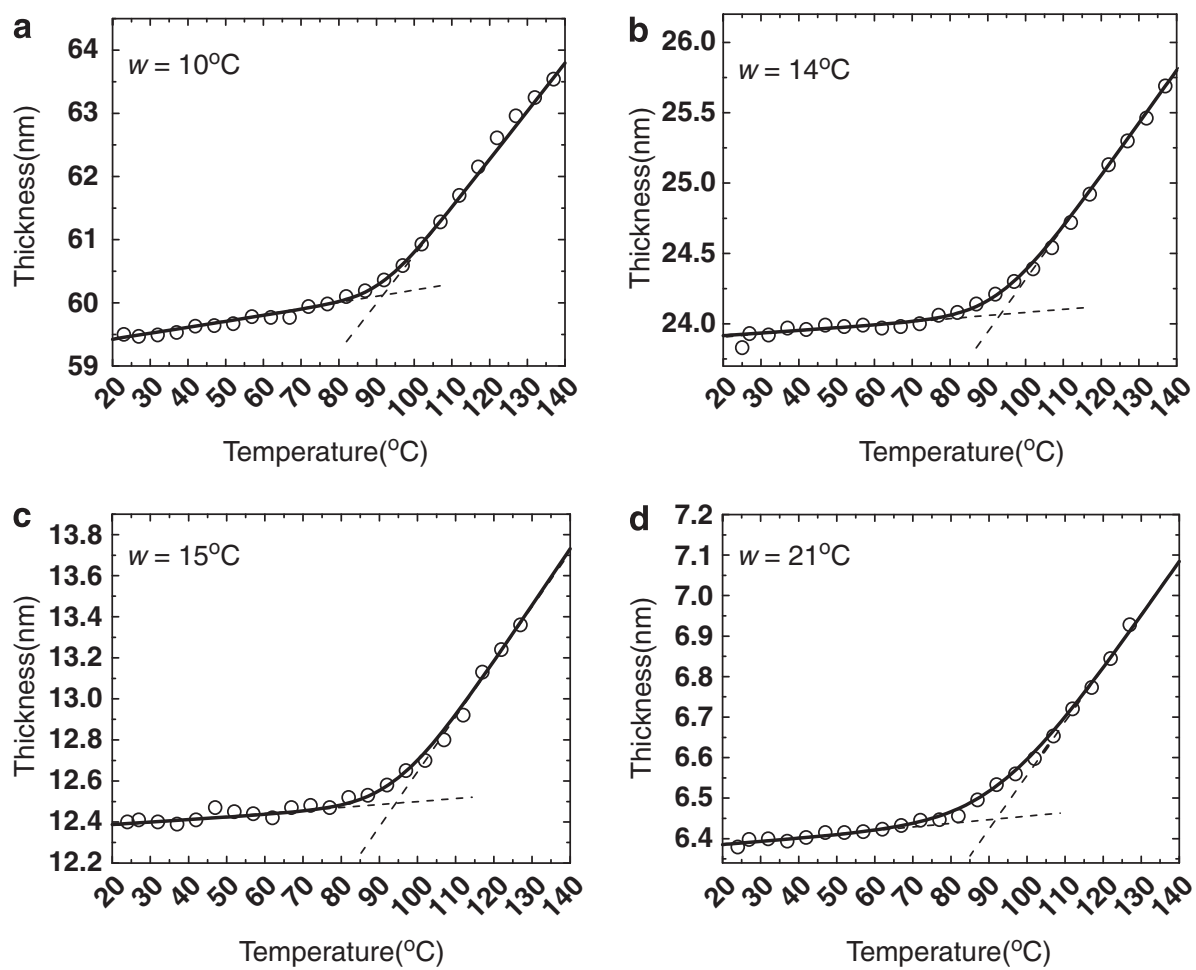

Figure 4 Temperature dependence of thickness measured at a heating rate of $0.5^{\circ} \mathrm{C} \mathrm{min}{ }^{-1}$. Initial thicknesses at room temperature were $h_{0}=59.50 \mathrm{~nm}$ (a), $23.83 \mathrm{~nm}$ (b), $12.40 \mathrm{~nm}$ (c) and $6.40 \mathrm{~nm}$ (d). The obtained $w$ is also shown in each figure. Solid lines are the results of fits.

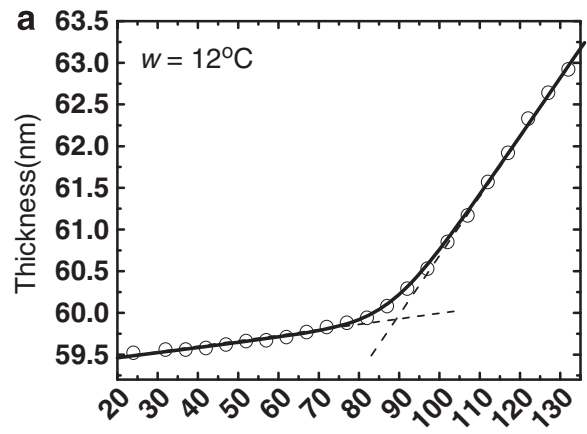

Temperature $\left({ }^{\circ} \mathrm{C}\right)$

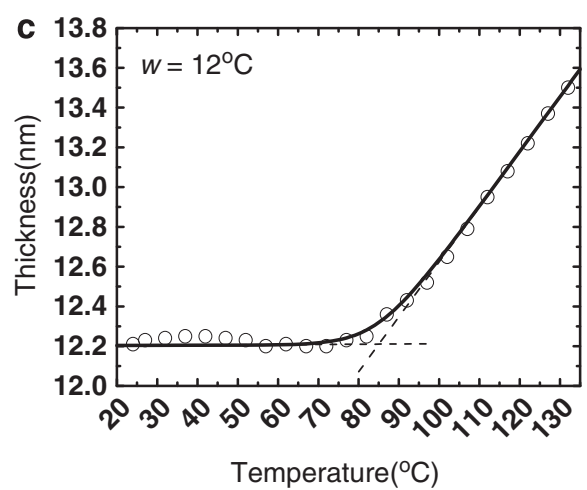

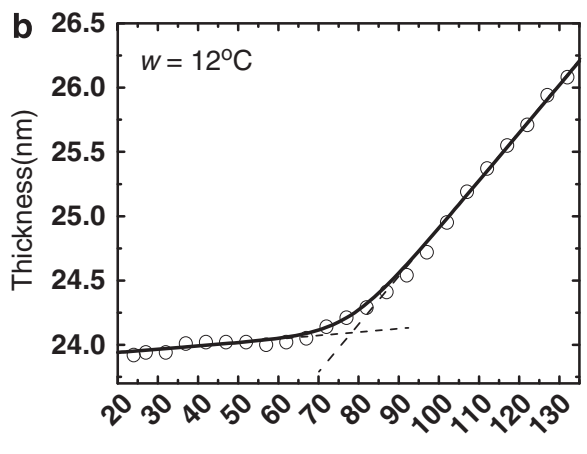

Temperature $\left({ }^{\circ} \mathrm{C}\right)$

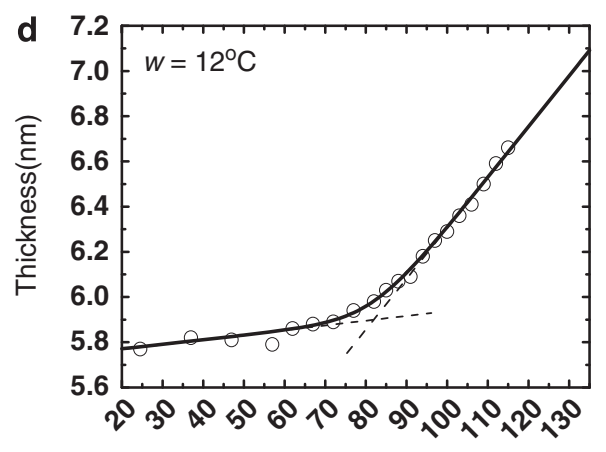

Temperature $\left({ }^{\circ} \mathrm{C}\right)$

Figure 5 Temperature dependence of thickness measured at a heating rate of $0.05{ }^{\circ} \mathrm{Cmin}^{-1}$. Initial thicknesses at room temperature were $h_{0}=59.50$ (a), 23.90 (b), 12.20 (c) and $5.80 \mathrm{~nm}$ (d). Solid lines are the results of fits, and $w$ is shown in each figure. 

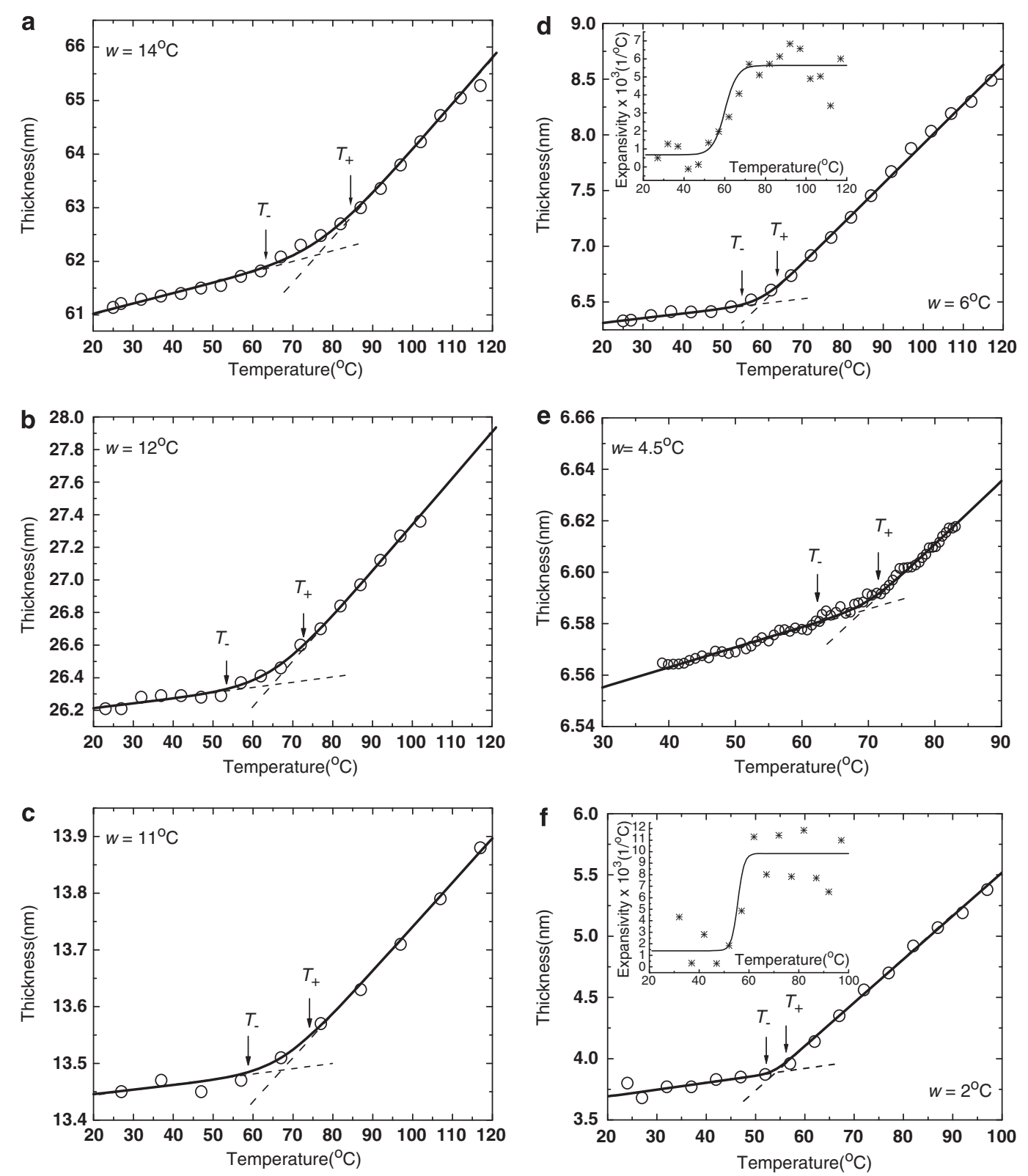

Figure 6 Temperature dependence of thickness measured at an ultraslow heating/cooling rate of $0.01{ }^{\circ} \mathrm{C} \mathrm{min}{ }^{-1}$. Initial thicknesses at room temperature were $h_{0}=61.10$ (a), 26.20 (b), 12.10 (c), 6.30 (d), 5.95 (e) and $3.80 \mathrm{~nm}$ (f). All the samples except (c) and (e) were measured under heating. $T_{+}$and $T_{-}$ indicate the two extremes of the transition. Inset in (d) and (f) shows the temperature dependence of thermal expansivity.

where $w_{\infty}\left(=12{ }^{\circ} \mathrm{C}\right)$ represents an average of $w$ over thicker films, and $k(q)$ represents a slope $k$ dependent on the heating rate $q$. The value $h_{\mathrm{c}}(q)$ corresponds to a critical thickness below which the narrowing or broadening of the glass transition occurs. For a 36-nm-thick PS film, the difference between $T_{\mathrm{g}}$ in the interfacial layer and $T_{\mathrm{g}}$ in the surface layer was estimated to be $11^{\circ} \mathrm{C},{ }^{8}$ which seems to be quite comparable with $w_{\infty}$ obtained in this study. The best-fit values of $k\left(0.5^{\circ} \mathrm{C} \mathrm{min}{ }^{-1}\right)$, $k\left(0.05^{\circ} \mathrm{C} \mathrm{min}^{-1}\right)$ and $k\left(0.01^{\circ} \mathrm{C} \mathrm{min}^{-1}\right)$ are $2.0 \pm 0.2, \sim 0.0$ and $-3.4 \pm 0.5 \mathrm{~nm}$, respectively. The values $h_{\mathrm{c}}\left(0.5^{\circ} \mathrm{C} \mathrm{min}^{-1}\right)$ and

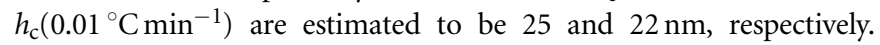
Because the previously estimated values of $h_{\mathrm{c}}$ for films with different molecular weights demonstrating a broadening of the glass transition is reported to be on the order of $20-30 \mathrm{~nm},{ }^{15-17,27,28}$ which is totally consistent with the values obtained in this study, there is a possibility that equation (2) still holds for glassy polymer films that show a narrowing of the glass transition. The $w$ of the PS film with $M_{\mathrm{W}}=8.35 \times 10^{5} \mathrm{~g} \mathrm{~mol}^{-1}$ measured at a cooling rate of $0.01^{\circ} \mathrm{C} \mathrm{min}^{-1}$ (' $X$ ') may indicate a more pronounced narrowing behavior that certainly deviates from the solid line fitted by the data of $M_{\mathrm{w}}=5.2 \times 10^{4} \mathrm{~g} \mathrm{~mol}^{-1}$ films obtained at the same rate. The possibility of molecular-weight dependence of $w$ under ultraslow temperature variations is worth mentioning. The authors thus believe that another comprehensive study with measuring variety of samples with different molecular weights is necessary for discussing this issue, which should eventually be explained in the near future.

In previous studies, ${ }^{17,27,29} w$ is defined as $T_{+}-T_{-}$. Although we already obtained $w$ from the fit to the data by adopting equation (1), we separately determined $T_{+}$and $T_{-}$using $h(T)$ curves as the 


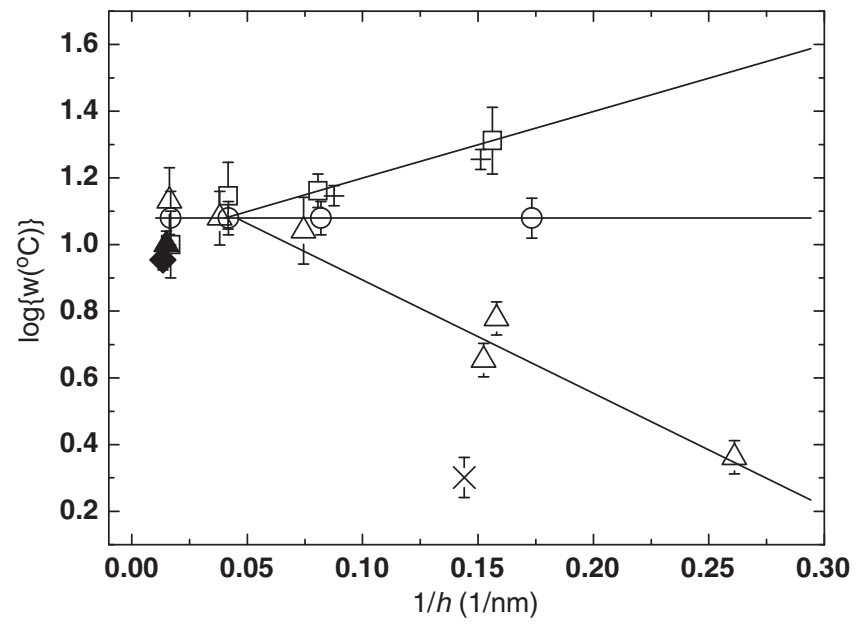

Figure 7 Logarithm of $w$ with error bars as a function of reciprocal film thickness. Lines represent a linear fit to the data using a function described in the text. The symbols $\square, \bigcirc$ and $\Delta$ represent $w$ of the film with $M_{\mathrm{w}}=5.2 \times 10^{4} \mathrm{~g} \mathrm{~mol}^{-1}$ measured at a heating rate (or cooling rate) of 0.5 , 0.05 and $0.01{ }^{\circ} \mathrm{C} \mathrm{min}^{-1}$, respectively. The symbols $\boldsymbol{\Delta}$ and $\downarrow$ represent $w$ of the films with $M_{\mathrm{w}}=2.34 \times 10^{5} \mathrm{~g} \mathrm{~mol}^{-1}$ measured at a heating rate of 0.5 and $0.01{ }^{\circ} \mathrm{C} \mathrm{min}{ }^{-1}$, respectively. The symbols + and $\times$ represent $w$ of the films with $M_{\mathrm{w}}=8.35 \times 10^{5} \mathrm{~g} \mathrm{~mol}^{-1}$ measured at a cooling rate of 0.5 and $0.01{ }^{\circ} \mathrm{C} \mathrm{min}^{-1}$, respectively.

temperatures at which the fitted curve of equation (1) deviates from linear fits in rubbery state or glassy state by $2 \%$; the linear fits and $T_{+}$ and $T_{-}$are indicated by dashed lines and arrows, respectively, in Figures 2-6 (arrows are shown only in Figure 6). Figure 8 shows the thickness dependence of $T_{+}$and $T_{-}$for three heating rates $(0.5,0.05$ and $\left.0.01{ }^{\circ} \mathrm{C} \mathrm{min}^{-1}\right)$. Although $T_{+}-T_{-}$obtained by this procedure may not necessarily be identical to $w$ in equation (1), we confirmed that within an experimental accuracy, the ratio of fitted $w$ in equation (1) to the obtained $\left(T_{+}-T_{-}\right)$is almost constant. This explains why broadening, no broadening and narrowing of the glass transition are also seen clearly from the difference between $T_{+}$and $T_{-}$(Figure 8).

Figure $8 \mathrm{a}$ shows the broadening for thinner films. At a heating rate of $0.5{ }^{\circ} \mathrm{C} \mathrm{min}^{-1}, T_{-}$indicates a trend toward decreasing with decreasing thickness, whereas $T_{+}$monotonously increases with decreasing thickness. Such a broadening of the glass transition in PS films is consistent with ellipsometric observations. ${ }^{17,29}$ For a 25 -nm-thick film ${ }^{17}$ and a 23 -nm-thick film, ${ }^{29} T_{-}$is reported to be $\sim 75^{\circ} \mathrm{C}$ and $T_{+}$is reported to be $\sim 110^{\circ} \mathrm{C}$; these values are close to the values shown in Figure 8a for the 23.8-nm-thick film. From Figure 8b, we confirm that the no-broadening behavior observed at a rate of $0.05^{\circ} \mathrm{C} \mathrm{min}-1$ is a consequence of the monotonously, somewhat identical decrease in $T_{+}$and $T_{-}$with decreasing thickness, which appears to keep $T_{+}-T_{-}$constant. Figure $8 \mathrm{c}$ shows that the narrowing phenomenon under the ultraslow heating rate $\left(0.01{ }^{\circ} \mathrm{C} \mathrm{min}^{-1}\right)$ can be considered as a result of a drastic decrease in $T_{+}$and a weak decrease in $T_{-}$with decreasing thickness.

A three-layer model, with the three layers characterized by different characteristic temperatures below which the falling-out-of-equilibrium occurs, has been effectively used to explain the width of the glass transition upon cooling. ${ }^{17,29}$ It might also effectively explain our observations, which were mainly performed while heating. For a topmost surface layer of PS exposed to air, the falling-out-of-equilibrium is expected to occur at a lower temperature than that for the bulk-like interior layer because of the enhanced mobility peculiar to the free surface. Therefore, the obtained $T_{-}$would be an effective
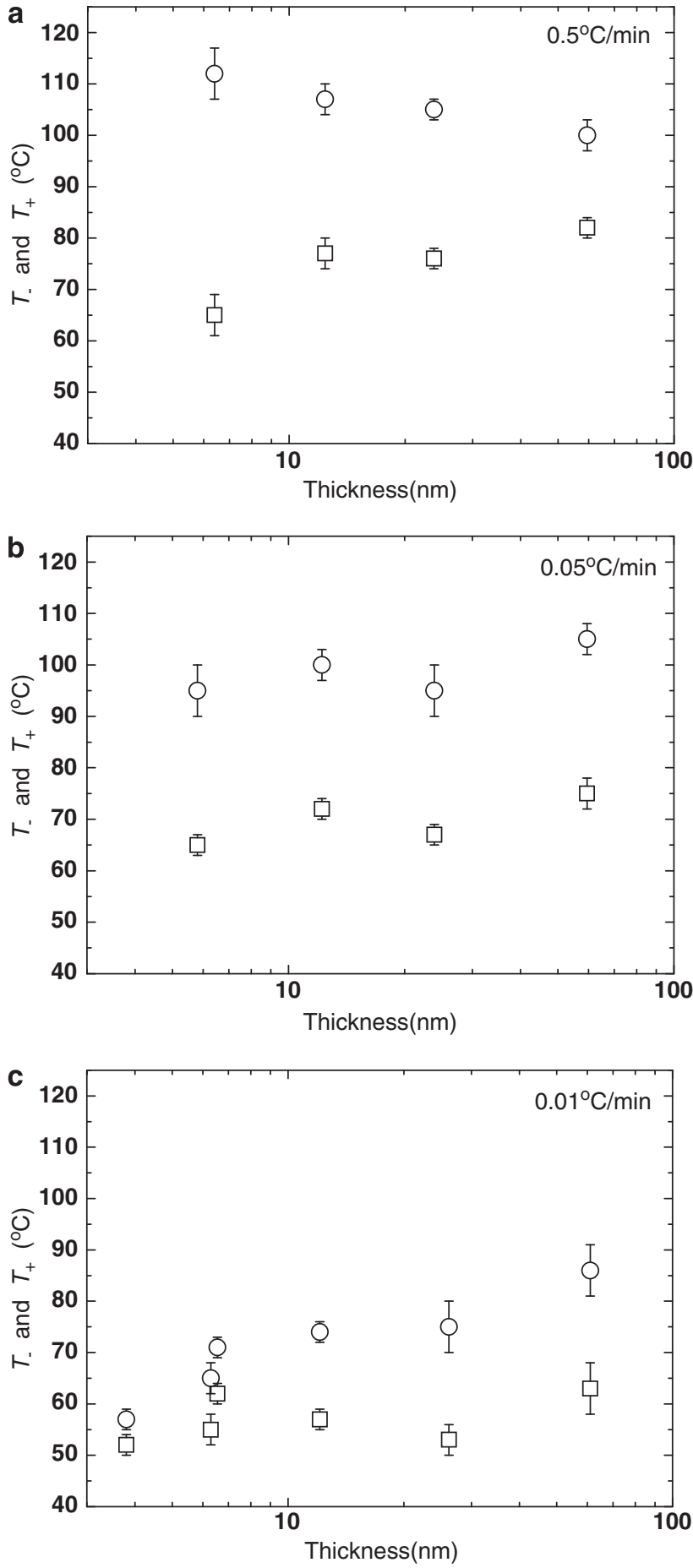

Figure 8 Thickness dependence of $T_{+}(O)$ and $T_{-}(\square)$. Scanning rates are 0.5 (a), 0.05 (b) and $0.01^{\circ} \mathrm{C} \mathrm{min}^{-1}$ (c).

measure telling us the boundary separating the out-of-equilibrium regime from the equilibrium regime in such a topmost layer. On the other hand, the interfacial layer near the substrate is expected to have a lower mobility. In this case, the falling-out-of-equilibrium is expected to occur at a higher temperature near $T_{+}$for thin, supported glassy films. It is also likely that the mobility in the substrate interface layer of ultrathin films under the ultraslow heating condition is significantly higher than the mobility upon heating at the conventional rate. Such 
Table $1 \alpha_{\text {glass }}, \alpha_{\text {melt }}$ and $w$ of polystyrene films $\left(M_{\mathrm{w}}=5.2 \times 10^{4} \mathrm{~g} \mathrm{~mol}^{-1}, R_{\mathrm{g}} \sim 6 \mathrm{~nm}\right)$ obtained from the temperature-thickness profiles measured at different scan rates (Figure $4\left(0.5^{\circ} \mathrm{C} \mathrm{min}-1\right)$, Figure $5\left(0.05^{\circ} \mathrm{C} \mathrm{min}^{-1}\right)$ and Figure $6\left(0.01^{\circ} \mathrm{Cmin}^{-1}\right)$ )

\begin{tabular}{|c|c|c|c|c|c|c|}
\hline \multirow[b]{2}{*}{ Rate $\left({ }^{\circ} \mathrm{Cmin}^{-1}\right)$} & \multicolumn{3}{|c|}{$\sim 60 \mathrm{~nm}$} & \multicolumn{3}{|c|}{$\sim 24 \mathrm{~nm}$} \\
\hline & $\alpha_{\text {glass }}\left(\times 10^{-4}{ }^{\circ} \mathrm{C}^{-1}\right)$ & $\alpha_{m e l t}\left(\times 10^{-3}{ }^{\circ} \mathrm{C}^{-1}\right)$ & $w\left({ }^{\circ} \mathrm{C}\right)$ & $\alpha_{\text {glass }}\left(\times 10^{-4}{ }^{\circ} \mathrm{C}^{-1}\right)$ & 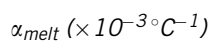 & $w\left({ }^{\circ} \mathrm{C}\right)$ \\
\hline $0.05^{a}$ & $1.0 \pm 0.1$ & $1.2 \pm 0.1$ & $12 \pm 2$ & $1.1 \pm 0.3$ & $1.5 \pm 0.1$ & $12 \pm 1$ \\
\hline $0.01^{a}$ & $2.9 \pm 0.5$ & $1.3 \pm 0.1$ & $14 \pm 2$ & $1.1 \pm 0.3$ & $1.1 \pm 0.1$ & $12 \pm 2$ \\
\hline Rate $\left({ }^{\circ} \mathrm{Cmin}-1\right)$ & $\alpha_{\text {glass }}\left(\times 10^{-4}{ }^{\circ} \mathrm{C}^{-1}\right)$ & $\alpha_{m e l t}\left(\times 10^{-3{ }^{\circ}} \mathrm{C}^{-1}\right)$ & $w\left({ }^{\circ} \mathrm{C}\right)$ & $\alpha_{\text {glass }}\left(\times 10^{-4}{ }^{\circ} \mathrm{C}^{-1}\right)$ & $\alpha_{m e l t}\left(\times 10^{-3}{ }^{\circ} \mathrm{C}^{-1}\right)$ & $w\left({ }^{\circ} \mathrm{C}\right)$ \\
\hline $0.5^{\mathrm{a}}$ & $1.0 \pm 0.3$ & $2.2 \pm 0.2$ & $15 \pm 1$ & $1.2 \pm 0.2$ & $1.9 \pm 0.2$ & $21 \pm 2$ \\
\hline $0.05^{a}$ & $0.01 \pm 0.01$ & $2.2 \pm 0.1$ & $12 \pm 1$ & $3.4 \pm 0.2$ & $3.9 \pm 0.1$ & $12 \pm 1$ \\
\hline $0.01^{\mathrm{a}}$ & & & & $6.7 \pm 0.9$ & $5.6 \pm 0.5$ & $6 \pm 1$ \\
\hline $0.01^{\mathrm{b}}$ & $0.6 \pm 0.3$ & $0.57 \pm 0.09$ & $11 \pm 2$ & $1.2 \pm 0.1$ & $0.37 \pm 0.04$ & $4.5 \pm 1.0$ \\
\hline
\end{tabular}

${ }^{\text {a Heating. }}$

booling.

increased mobility near the substrate would come from the enhanced mobility in the free-surface region, which increases the degree of homogeneity by decreasing the difference of mobility among the three layers. Measurements of a 14-nm-thick fluorescently labeled PS layer embedded in a thick PS layer ${ }^{8}$ showed that the enhanced mobility inherent in the free-surface region can propagate into the interior of the film as deep as $20-30 \mathrm{~nm}$, which is much longer than the length scale of a single cooperatively rearranging region reported for bulk PS $(\sim 3.5 \mathrm{~nm}) ;^{30}$ once the mobility of segments in the topmost surface layer is enhanced, it would yield a series of perturbations toward the adjacent interior layer, leading a dynamics perturbation into the interfacial layer. ${ }^{8,31,32}$ It is thus quite likely that in ultrathin films under such ultraslow temperature variation, the enhanced mobility in the surface region can slowly propagate into the interfacial layer via the interior layer, until it finally modifies local dynamics of the interfacial layer. Once substantially slower dynamics near the substrate are activated by the perturbation of cooperative dynamics originating in the surface layer under such ultraslow rates, the spatial variation in averaged dynamics across the film might become small enough to give rise to a narrowing of the glass transition. Time for redistribution of relaxation time in each layer might be an effective concept for helping us understand the critical heating/cooling rate below which the narrowing occurs. As the smallest value of $w\left(2{ }^{\circ} \mathrm{C}\right)$ obtained in this study happens to be close to the typical $w$ in free-standing films, ${ }^{19}$ our result may also give some insight into the dynamics of supported ultrathin glassy films and those of free-standing films.

From the slope of the thickness vs. temperature curve obtained at the rate of $0.5^{\circ} \mathrm{C} \mathrm{min}^{-1}$ (Figure $4 \mathrm{a}$ ), thermal expansivity of the glassy state $\alpha_{\text {glass }}$ for the thicker film $(\sim 60 \mathrm{~nm})$ is estimated as $1.6 \times 10^{-4}{ }^{\circ} \mathrm{C}^{-1}$ (as shown in Table 1 in which $\alpha_{\text {glass }}, \alpha_{\text {melt }}$ and $w$ are summarized), which is in full agreement with the literatures. ${ }^{25,29}$ The $\alpha_{\text {glass }}$ of the ultrathin film $(\sim 6.4 \mathrm{~nm})$ at the rate of $0.5^{\circ} \mathrm{C} \mathrm{min}^{-1}$ is also obtained as $1.2 \times 10^{-4}{ }^{\circ} \mathrm{C}^{-1}$, which is slightly smaller than that of the 60 -nm-thick film. However, $\alpha_{\text {glass }}$ of the ultrathin film $(\sim 6 \mathrm{~nm})$ significantly increased from $3.4 \times 10^{-4}$ to $6.7 \times 10^{-4}{ }^{\circ} \mathrm{C}^{-1}$, with decreasing heating rate from 0.05 to $0.01{ }^{\circ} \mathrm{C} \mathrm{min}^{-1}$ (Table 1 and the inset of Figure $6 \mathrm{~d}$ ). To the best of the authors' knowledge, such a marked increase in $\alpha_{\text {glass }}$ has not been reported for bulk samples. The trend for noticeable increase in $\alpha_{\text {glass }}$ obtained at the ultraslow heating rate is remarkable for the thinnest film $(\sim 4 \mathrm{~nm})$ at a heating rate of
$0.01{ }^{\circ} \mathrm{C} \mathrm{min}^{-1}$, in which $\alpha_{\text {glass }}$ is estimated as $1.4 \times 10^{-3}{ }^{\circ} \mathrm{C}^{-1}$ (inset of Figure 6f; not shown in Table 1). Our result on large $\alpha_{\text {glass }}$ values of ultrathin films ( $\sim 4$ and $6 \mathrm{~nm}$ ) observed only at the ultraslow heating might be consistent with the ellipsometric studies, if we would take some extrapolation of the fits to the data measured at conventional rates. ${ }^{17,33}$ Expansivity above $T_{\mathrm{g}}, \alpha_{\text {melt }}$ of thick films $(\sim 60 \mathrm{~nm})$ is estimated as $1.2 \times 10^{-3}{ }^{\circ} \mathrm{C}^{-1}$, which almost coincides with $\alpha_{\text {melt }}$ of bulk samples $\left(1.02 \times 10^{-3}{ }^{\circ} \mathrm{C}^{-1}\right) .{ }^{15}$ Contrary to the thicker films and bulk samples, $\alpha_{\text {melt }}$ of ultrathin films $\left(h_{0}=\sim 6\right.$ and $4 \mathrm{~nm}$, that is $\left.h_{0}<2 R_{\mathrm{g}}\right)$ measured at a heating rate of $0.01{ }^{\circ} \mathrm{C} \mathrm{min}^{-1}$ are $5.6 \times 10^{-3}{ }^{\circ} \mathrm{C}^{-1}$ (inset of Figure $6 \mathrm{~d}$ ) and $9.8 \times 10^{-3}{ }^{\circ} \mathrm{C}^{-1}$ (inset of Figure $6 \mathrm{f}$; not shown in Table 1), indicating much larger values than those of bulk samples. Such a large $\alpha_{\text {melt }}$ of ultrathin PS films is also reported in another XR study collected at conventional heating rate, ${ }^{27}$ where the maximum $\alpha_{\text {melt }}$ was estimated to be $5.6 \times 10^{-3}{ }^{\circ} \mathrm{C}^{-1}$. In an ultraslow cooling measurement recorded at the rate of $0.01{ }^{\circ} \mathrm{C} \mathrm{min}^{-1}$, the values of $\alpha_{\text {glass }}$ and $\alpha_{\text {melt }}$ of a 6 -nm-thick film are obtained as $1.2 \times 10^{-4}$ and $3.7 \times 10^{-4}{ }^{\circ} \mathrm{C}^{-1}$, respectively; these expansivities are in striking contrast to those of the film, with corresponding thickness measured at the ultraslow heating, although there is no significant difference between the width $w$ at ultraslow heating $\left(w=6.0 \pm 1.0^{\circ} \mathrm{C}\right)$ and that at ultraslow cooling $\left(w=4.5 \pm 1.0^{\circ} \mathrm{C}\right)$. The similarity between $w$ obtained under ultraslow heating and that under ultraslow cooling would indicate the robustness of the narrowing phenomenon in ultrathin films at ultraslow heating and cooling rates. We consider that such an unusual behavior in $\alpha_{\text {glass }}$ and $\alpha_{\text {melt }}$ indicated by the ultrathin films under ultraslow heating/cooling conditions contains some significant meaning which would become an important clue to a deeper understanding of the peculiar physical properties of severely confined polymeric glassy materials, including the broadening to narrowing transition, and should be investigated comprehensively in the near future.

\section{CONCLUSIONS}

The thickness of PS thin films has been precisely investigated by XR measurements at various heating and cooling rates. With decreasing thickness, the width of the glass transition shows an appreciable variation that depends on the rate of temperature variation: broadening at a rate of $0.5^{\circ} \mathrm{C} \mathrm{min}{ }^{-1}$, no broadening at a rate $0.05^{\circ} \mathrm{Cmin}^{-1}$ and narrowing at a rate of $0.01{ }^{\circ} \mathrm{C} \mathrm{min}{ }^{-1}$. Our results strongly suggest 
that, under sufficiently slow temperature variation, the enhanced mobility peculiar to the free-surface region slowly propagates deep into the interior of the films and causes complete relaxation in the interfacial region near the substrate, where relaxation is hindered under a conventional rate of temperature variation. The thickness below which the narrowing of glass transition is remarkably noticeable is $20-30 \mathrm{~nm}$, which is much larger than the length scale of a single cooperatively rearranging region reported for bulk PS.

\section{ACKNOWLEDGEMENTS}

We are grateful to Dr K Shimizu and Professor H Terauchi for valuable discussion and critical reading of the manuscript. We are also thankful to $\mathrm{N}$ Koyasu and $\mathrm{K}$ Ishimoto for their support in XR and atomic force microscopy measurements. This study was financially supported by Promotion and Mutual Aid Cooperation for Private Schools in Japan (the Science Research Promotion fund in 2006-2008) and Kwansei Gakuin University (Kwansei Gakuin University Joint Research Fund, 2009).

1 Ediger, M. D., Angell, C. A. \& Nagel, S. R. Supercooled liquids and glasses. J. Phys. Chem. 100, 13200 (1996).

2 Bueche, F. Mobility of molecules in liquids near the glass temperature. J. Chem. Phys. 30, 748 (1959).

3 Adam, G. \& Gibbs, J. H. On the temperature dependence of cooperative relaxation properties in glass-forming liquids. J. Chem. Phys. 43, 139 (1965).

4 Alcoutlabi, M. \& McKenna, G. B. Effect of confinement on material behavior at the nanometre size scale. J. Phys.: Condens. Matter 17, R461 (2005).

5 Forrest, J. A. \& Dalnoki-Veress, K. The glass transition in thin polymer films. Adv. Colloid Interface Sci. 94, 167 (2001).

6 Papaléo, R. M., Leal, R., Carreira, W. H., Barbosa, L. G., Bello, I . \& Bulla, A. Relaxation times of nanoscale deformations on the surface of a polymer thin film near and below the glass transition. Phys. Rev. B 74, 094203 (2006).

7 Fakhraai, Z. \& Forrest, J. A. Measuring the surface dynamics of glassy polymers. Science 319, 600 (2008).

8 Ellison, C. J. \& Torkelson, J. M. The distribution of glass-transition temperatures in nanoscopically confined glass formers. Nat. Mater. 2, 695 (2003).

9 Priestley, R. D., Ellison, C. J., Broadbelt, L. J. \& Torkelson, J. M. Structural relaxation of polymer glasses at surfaces, interfaces, and in between. Science 309, 456 (2005).

10 van Zanten, J. H., Wallace, W. E. \& Wu, W. L. Effect of strongly favorable substrate interactions on the thermal properties of ultrathin polymer films. Phys. Rev. E 53, R2053 (1996).

11 Napolitano, S. \& Wübbenhorst, M. Dielectric signature of a dead layer in ultrathin films of a nonpolar polymer. J. Phys. Chem. B 111, 9197 (2007).

12 Tsui, O. K. C., Russell, T. P. \& Hawker, C. J. Effect of interfacial interactions on the glass transition of polymer thin films. Macromolecules 34, 5535 (2001).
13 Qi, D., Fakhraai, Z. \& Forrest, J. A. Substrate and chain size dependence of near surface dynamics of glassy polymers. Phys. Rev. Lett. 101, 096101 (2008).

14 Hall, D. B., Hooker, J. C. \& Torkelson, J. M. Ultrathin polymer films near the glass transition: effect on the distribution of $\alpha$-relaxation times as measured by second harmonic generation. Macromolecules 30, 667 (1997).

15 Fukao, K. \& Miyamoto, Y. Glass transitions and dynamics in thin polymer films: dielectric relaxation of thin films of polystyrene. Phys. Rev. E 61, 1743 (2000).

16 Serghei, A., Tress, M. \& Kremer, F. Confinement effects on the relaxation time distribution of the dynamic glass transition in ultrathin polymer films. Macromolecules 39, 9385 (2006).

17 Kawana, S. \& Jones, R. A. L. Character of the glass transition in thin supported polymer films. Phys. Rev. E 63, 021501 (2001).

18 Mattsson, J., Forrest, J. A. \& Börjesson, L. Quantifying glass transition behavior in ultrathin free-standing polymer films. Phys. Rev. E 62, 5187 (2000).

19 Dalnoki-Veress, K., Forrest, J. A., Murray, C., Gigault, C. \& Dutcher, J. R. Molecular weight dependence of reductions in the glass transition temperature of thin, freely standing polymer films. Phys. Rev. E 63, 031801 (2001).

20 Sharp, J. S. \& Forrest, J. A. Dielectric and ellipsometric studies of the dynamics in thin films of isotactic poly(methylmethacrylate) with one free surface. Phys. Rev. E 67, 031805 (2003).

21 Serghei, A., Huth, H., Schick, C. \& Kremer, F. Glassy dynamics in thin polymer layers having a free upper interface. Macromolecules 41, 3636 (2008).

22 Fakhraai, Z. \& Forrest, J. A. Probing slow dynamics in supported thin polymer films. Phys. Rev. Lett. 95, 025701 (2005)

23 Efremov, M. Y., Olson, E. A., Zhang, M., Zhang, Z. \& Allen, L. H. Glass transition in ultrathin polymer films: calorimetric study. Phys. Rev. Lett. 91, 085703 (2003).

24 Badrinarayanan, P., Zheng, W., Li, Q. X. \& Simon, S. L. The glass transition temperature versus the fictive temperature. J. Non-Cryst. Solids 353, 2603 (2007).

25 Miyazaki, T., Nishida, K. \& Kanaya, T. Thermal expansion behavior of ultrathin polymer films supported on silicon substrate. Phys. Rev. E 69, 061803 (2004).

26 Fukao, K. \& Miyamoto, Y. Slow dynamics near glass transitions in thin polymer films. Phys. Rev. E 64, 011803 (2001).

27 Bhattacharya, M., Sanyal, M. K., Geue, Th. \& Pietsch, U. Glass transition in ultrathin polymer films: a thermal expansion study. Phys. Rev. E 71, 041801 (2005).

28 Napolitano, S., Lupascu, V. \& Wübbenhorst, M. Temperature dependence of the deviations from bulk behavior in ultrathin polymer films. Macromolecules 41, 1061 (2008).

29 Kim, S., Hewlett, S. A., Roth, C. B. \& Torkelson, J. M. Confinement effects on glass transition temperature, transition breadth, and expansivity: comparison of ellipsometry and fluorescence measurements on polystyrene films. Eur. Phys. J. E 30, 83 (2009)

30 Ellison, C. J., Mundra, M. K. \& Torkelson, J. M. Impacts of polystyrene molecular weight and modification to the repeat unit structure on the glass transition-nanoconfinement effect and the cooperativity length scale. Macromolecules 38, 1767 (2005).

31 Roth, C. B., McNerny, K. L. Jager, W. F. \& Torkelson, J.M. Eliminating the enhanced mobility at the free surface of polystyrene: fluorescence studies of the glass transition temperature in thin bilayer films of immiscible polymers. Macromolecules 40, 2568 (2007)

32 Roth, C. B. \& Torkelson, J.M. Selectively probing the glass transition temperature in multilayer polymer films: equivalence of block copolymers and multilayer films of different homopolymers. Macromolecules 40, 3328 (2007).

33 Keddie, J. L., Jones, R. A. L. \& Cory, R. A. Size-dependent depression of the glass transition temperature in polymer films. Eur. Phys. Lett. 27, 59 (1994). 